\title{
SUCCESS OF ORGANIZATION DEVELOPMENT: MODELING
}

\author{
Vasilii Trenev $^{1}$, Vitaly Krupenin ${ }^{2,3}$ \\ ${ }^{1}$ Moscow State University of Education, Russia; ${ }^{2}$ Mechanical Engineering Research Institute of the \\ Russian Academy of Sciences, Russia; ${ }^{3}$ Moscow Polytechnic University, Russia \\ vttrenev@gmail.com, krupeninster@gmail.com
}

\begin{abstract}
A model for successful development of an organization (industrial or agro-industrial complex) as a mechanism for achieving the region of "successful" states in a multidimensional space of indicators is proposed. The use of the concept of "preferred solution trajectory" makes it possible to move from the multicriteria selection problem to the simple problem of optimizing a meaningfully interpreted function. Examples of models based on differential equations, which are qualitatively analysed, are given.The problem of the influence of the structure of the team with workers of various types, in particular, conformists and nonconformists on the possibility of achieving the success of development, is being investigated.
\end{abstract}

Keywords: development, development management, success, a trajectory of preferred solutions, the structure of the collective.

\section{Introduction: the concept of "successful development"}

In the practice of strategic management, the Balanced Scorecard or BSC method is often used to assess the current and target state of an organization [1]. Its main idea is to provide a scorecard in the form of four groups:

- financial indicators;

- customer or external environment indicators (relations with customers, partners, counterparties, market size, market share in the target segment and etc.);

- indicators related to internal business processes (production, supply, sales, innovations and etc.);

- indicators characterizing the company's ability for learning and growth (people with their abilities, skills and motivation, information systems, organizational procedures that ensure interaction between participants of the process and determine a solution making system).

Each category of such groups forms development goals and describes the "desired perspectives" of the company.

In the categories of these indicators ("success criteria"), based on the forecast information and taking into account the already existing knowledge and representations in the mind of the manager both the existing image of the state of the managed object as well as the desired image or the goal of company's development, are formed.

A comprehensive idea is formed about the essential properties of the object and about main connections between them. This model is often crude and inaccurate, but it gives the manager an opportunity to correlate parts of the process as a whole, "to capture the situation at a glance", which is especially important in goal formation processes.

Comparison of this model with the desired image-goal leads to a problem that considerably determines the direction of searching for the management action.

Thus, each company forms within such indicators its own "vision" - a descriptive concept of the desired state or perspective.

In a manner of speaking, we can single out a number of factors ("success criteria"), the categories of which represent the image of a "successful" company. A simply connected set is formed, belonging to which corresponds to the "successful" state of the company.

We can formulate several hypothesis and definitions.

Hypothesis 1 . There is a multi-criteria space, which evaluates the activities of each organization by its criteria (the space of "success criteria").

Definition 1. The "successful" development of the company will be interpreted as the long-term correspondence to expectations significant for a management team, as well as desirable "visions" of the company's image. 
Hypothesis 2. In the space of indicators ("success criteria") you can specify a simply connected set $\Phi^{*}$ (the development goal), belonging to which corresponds to the "successful" state of the company - the "set of successful states" - Fig. 1.

The $\Phi^{*}$ set can be defined as an area (or a discrete set of dots), as it is used in planning practice [2; $3]$. The $\Phi^{*}$ set can be defined in various ways, for example, implicitly - by means of some preference relation or an optimizing functional:

$$
\begin{gathered}
\Phi^{*}=\left\{\phi^{*} \mid \phi^{*}=\arg \text { opt } f(\phi, y)\right\} ; \\
\phi \in \Phi \\
y \in X \backslash \Phi
\end{gathered}
$$

However, initially in the categories of selected "success criteria," the system does not fall into the "set of desired states". This "state of success" is desirable, but at the initial moment is unattainable Fig. 1.

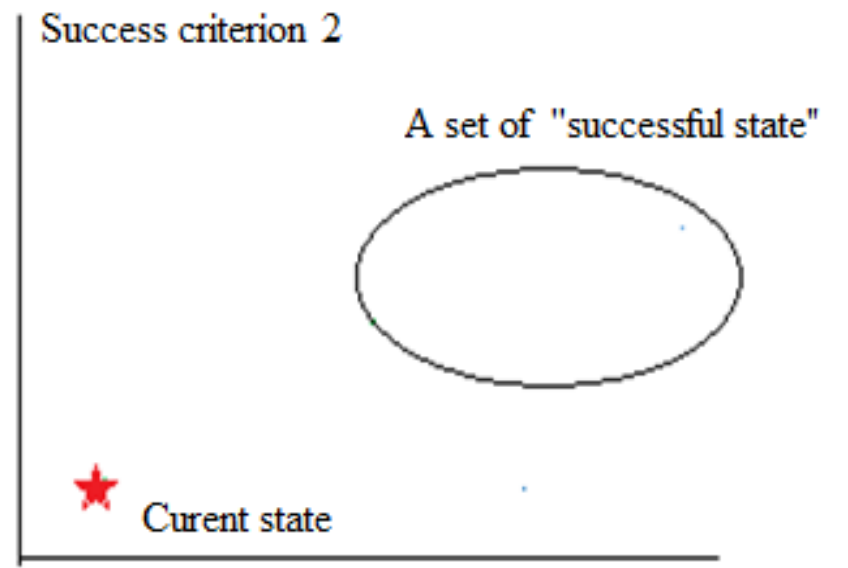

\section{Success criterion 1}

Fig. 1. Current state is outside the set of "successful states"

The problem of successful development of the company will be understood as the problem of forming its properties, allowing to get into the "set of successful states". The hitting of this set can be considered a criterion for achieving a "success" - Fig. 2.

The space of "success criteria" can be considered metric without loss of generality. Hence, if we introduce any metric concept, then the distance from the current state to the boundary of the set of "success states" (in the categories of the selected metric) can be considered a measure of "success achievement".

\section{Success criterion 2}

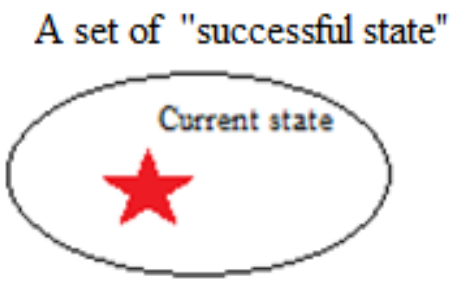

Success criterion 1

Fig. 2. Criterion for achieving "success" - current state is within the set of "successful states" 
Definition 2. "Success achievement" is measured by the distance from the current state to the boundary of the set of "success states" (in the categories of the selected metric) - Fig. 3 .

The current state is determined by the attainability domain (or set) - the area of possible values of system states - Fig. 3

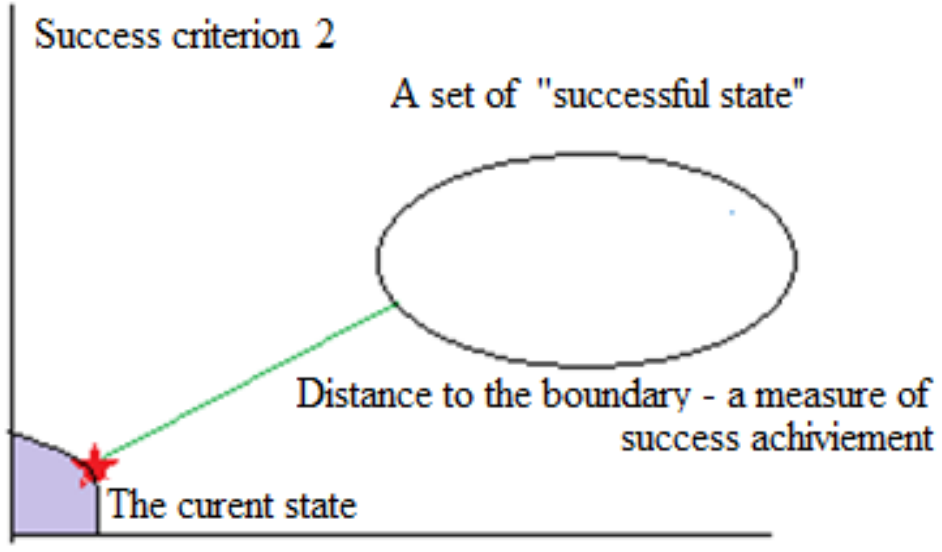

\section{Success criterion 1}

Fig. 3. Area of possible states determines attainable values for current states

The development management is aimed at the processes of deformation of an area of possible values. If an area of possible values is deformed, the optimal solution closest to the "area of success" will shift to it - Fig. 4.

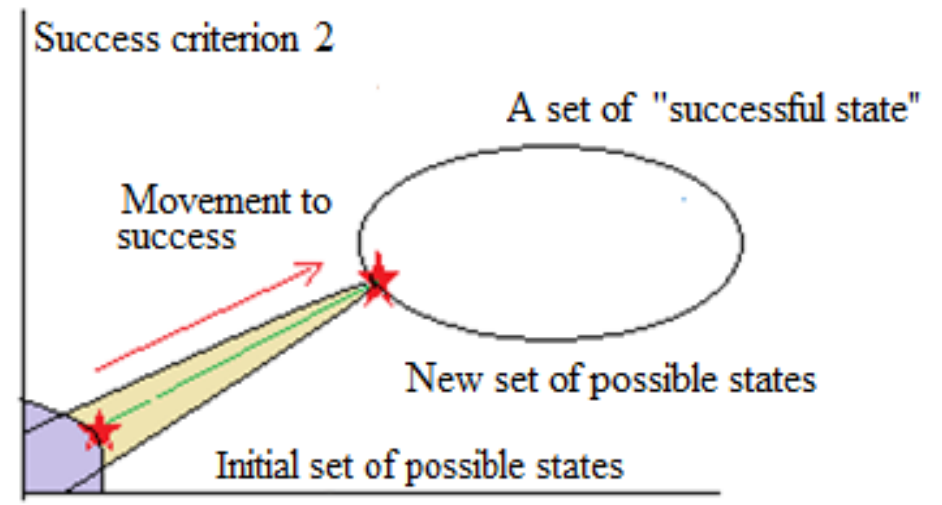

Success criterion 1

Fig. 4. Movement to success is deformation of area of possible states before crossing with area of "successful states"

\section{Modeling the possibility of achieving success by some team of performers (workers)}

Without loss of generality, we may assume that $\Phi$ space includes $\Gamma_{\phi}(\xi)$ line - a "trajectory of preferred states" $\phi^{*}$, which determines the "movement" of the system from the existing state to the "desired state" [2]. This "movement" is determined by "management actions" deforming an area of possible states (adding and redistributing resources, changing system parameters, etc.)

Hypothesis 3. A criteria space includes the trajectory of preferred solutions $\Gamma_{\phi}(\xi)$ :

$$
\Phi^{*}=\left\{\phi^{*} \mid \phi^{*}=\Gamma_{\phi}\left(\xi^{*}\right), \xi^{*}[0,1]\right\},
$$

where $\Gamma_{\phi}$-line (without loops) in $\Phi$ space (i.e. the trajectory);

$\phi^{*}$ - preferred (the closest from the currently possible states to the desired one) system states.

It seems like maximization problem is actual here: 


$$
\xi \rightarrow \max .
$$

However, in reality, it does not make sense since, in practice, multiple increases of a group of the system indicators lead to its unbalance, non-viability. There are new "bottlenecks" [4-7] - new significant (previously not considered in the model) factors. For example, an ill-conceived increase of production capacities of an industrial organization will most likely result in overproduction, freezing of circulating assets in unsold products, stocks of raw materials, "unnecessary" leasing payments and, ultimately, bankruptcy. Therefore, it is reasonable to accept the following hypothesis that for each criterion there is a reasonable range of "desirable values", defined by the conceptual model of perspective desired state of the company.

Hypothesis 4. The "set of successful states" in the criteria space can be enclosed in a sphere (or circle) of finite radius $\theta$.

Further, we'll consider, that $\xi \in(-\theta,+\theta)$, where $\theta<<\theta$. And value $\xi<\theta$ corresponds to "unattainability" of an area of success.

Value $\xi \in(-\theta,+\theta)$ corresponds to "attainability" of an area of success.

Value $\xi>\theta$ corresponds to "by-passing" of an area of success.

Problem set up. The management problem, in this case, is reduced to the selection of management actions and the change in the parameters of the system, which make it possible to advance along the trajectory $\Gamma_{\phi}$ from the state $\xi<\theta$ to the state $\xi \in(-\theta,+\theta)$.

Basically, the above arguments allow us to translate the multi-criteria optimization problem (work in a multidimensional criteria space) into the optimization problem for the scalar function $\xi(t)$ (success function) describing the most preferential solutions moving along the trajectory [2].

Modeling the possibility of achieving success by some team of performers (workers).

General definitions.

Success. Let $\xi=\xi(t)$ be the current value of the success function. It is said that success of the rank " $\varepsilon$-T" is achieved, if there exists $\varepsilon$ value, that for its fixed value in some neighborhood of zero $\varepsilon\left(-\varepsilon_{0}, \varepsilon_{0}\right)$, there is value $T>0$ such that for all time instants $0<t<T: \xi(t)=O(\varepsilon)$.

The meaning of the definition is that in terms of the problem under consideration the function can approximately be equal to zero and remain so for a significant time period.

Inertia coefficient $\mu-$ is not defined. It is a measure of the resistance of the objects under consideration to start moving to success or abandon it.

Tendency $\xi_{t}(t)$ - time derivative of the success function.

Global management on the way to success is a differential function by the set of arguments factors that are taken into account, when building a model of the movement of an object (for example, a team) to success in the space of criteria. The designation: $R\left(t, \xi, \xi_{t}, \ldots\right)$, where $\mathrm{t}$ is time, indexation with respect to $\mathrm{t}$ denotes differentiation, other arguments of the function $R$ are described below; the dots denote the ability to add other variables.

The performance factor $c \geq c_{0}>0$ is a measure of the availability of workers in the team having the notion that success is achievable only if $\xi(t) \approx 0$ and planning their actions in accordance with information about the values of the function $\xi(t)$ and only about it.

The $c_{0}$ value is the maximum permissible minimum of performers, which ensure the life activity of the collective (enterprises, groups of enterprises, etc.)

Conformists are workers, who mainly follow the tendency of $\xi_{t}(t)$ progress towards success and are striving to strengthen this tendency. The coefficient of conformism $a>0$ is a measure of conformists present in the collective.

Realists are workers, who mainly follow the tendency towards success $\xi_{t}(t)$ and understand that it is necessary to provide reasonable resistance to the tendency. The coefficient of realism $b>0-\mathrm{a}$ measure of realists present in the collective.

Trained realists are realists, workers, who mainly follow the tendency towards success $\xi_{t}(t)$ and understand that it is necessary to provide reasonable resistance to the tendency. And this resistance grows with the intensification of negative tendencies - as a result of the strengthening of the influence 
of the negative role of conformists. The coefficient of realism $b>0$ - a measure of realists present in the collective.

Notes.

Nonadditivity. Depending on many factors, the same member of the collective can play several roles or perform other roles. We will consider such models in subsequent work.

Ordering relationship. We will assume, that there is always $|c|>|a|$ and $|c|>|b|$

Basic equation.

We write the relation describing the change in tendencies in finite differences:

$$
\mu \xi_{n}(1+h)-\mu \xi_{t}(t)=R\left(t, \xi, \xi_{t}, \ldots\right) h,
$$

where $h$ - small change in the time, during which global management can be considered linear.

Hence it is easy to find:

$$
\mu \xi_{t t}(t)=R\left(t, \xi, \xi_{t}, \ldots\right) .
$$

Thus, the rate of tendency change is the result of global management in the space of criteria.

\section{Basic results}

The influence of "performers". Let us assume that the collective consists of the performers only. Their efforts are defined only by the deviation of $\xi(t)$ from 0 . Then the function $R\left(t, \xi, \xi_{\mathrm{t}}, \ldots\right)$ is:

$$
R\left(t, \xi, \xi_{t}, \ldots\right)=-c \xi \text {. }
$$

Then (4) is written as (6):

$$
\mu \xi_{t t}(t)+c \xi=0
$$

The solution of this elementary differential equation is well known [8; 9] and looks as follows:

$$
\xi(t)=D \cos (\Theta t+\lambda) ; \Theta^{2}=c \mu^{-1} .
$$

Constants $D$ and $\lambda$ depend on the initial conditions.

Let us consider the "sociological" meaning of the solution (6). It turns out that, if the collective of workers is managed in a way that the efforts of the team are aimed at achieving the goal $\xi=0$ and only there, then the goal is just unattainable, since the process turns out to be purely oscillatory and after reaching the goal the function $\xi$ leaves it ("passes by"). Success existing a sufficiently large time $T$ - is in principle not achievable (Fig. 5).

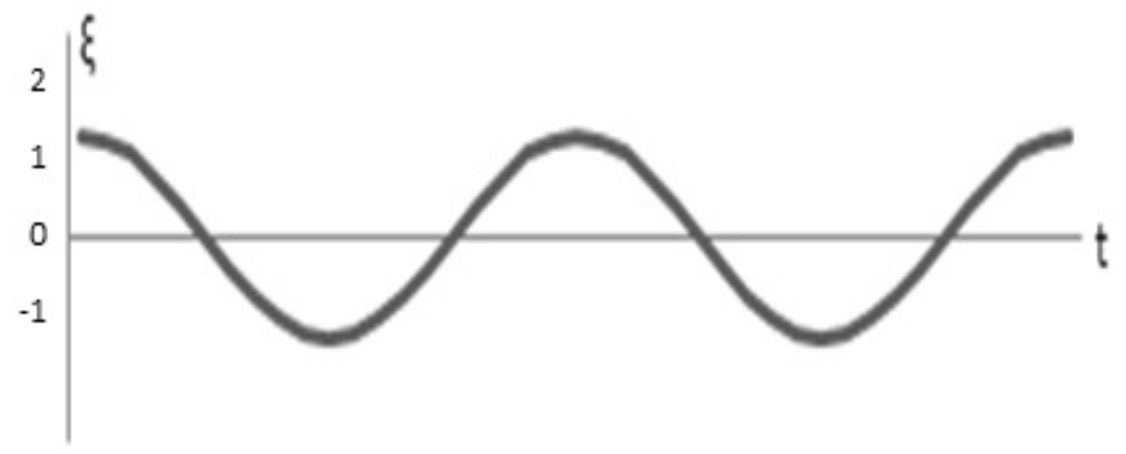

Fig. 5. It is not possible to hold on goal (stability $\xi \approx 0$ )

The influence of "conformists".

Let the collective, in addition to the performers, contain at least a small number of conformists. Their management action is represented as:

$$
R\left(t, \xi, \xi_{t}, \ldots\right)=-c \xi-a \xi_{t} .
$$

Equation (4) is: 


$$
\mu \xi_{t t}(t)+c \xi=-a \xi_{t}
$$

Thus, the general solution will be:

$$
\xi(t)=D \exp \left(\frac{a t}{2}\right) D \cos (\Theta t+\lambda) ; \Theta=\left(c^{2} \mu^{-2}+a^{2}\right)^{0.5}
$$

The conformism coefficient defines an increment of deviations of the process and the value of the function $\xi$ is moving from a goal that cannot be achieved (Fig. 6).

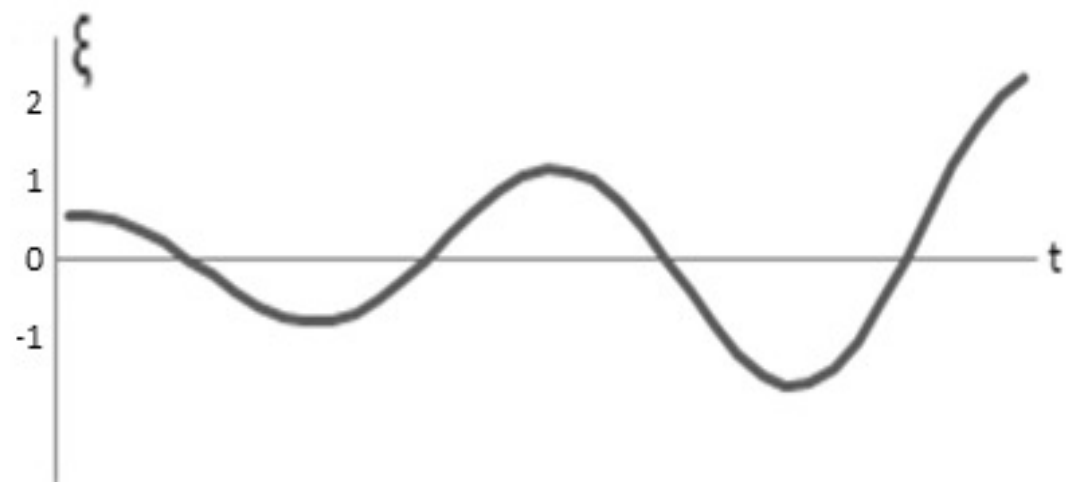

Fig. 6. System is unsparing. Goal (stability $\xi \approx 0$ ) cannot be achieved

The influence of "realists".

Obviously, within the framework of the model under consideration, the main role is played by the ratio between the coefficients of conformism and realism. The management action is represented as follows:

$$
R\left(t, \xi, \xi_{t}, \ldots\right)=-c \xi-a \xi_{t}+b \xi_{t} .
$$

In case of relists appearing in the collective, the equation (4) and its solution will be as follows (12), (13):

$$
\begin{gathered}
\mu \xi_{t t}(t)+c \xi=(b-a) \xi_{t}, \\
\xi(t)=D \exp \left(\frac{(a-b) t}{2}\right) D \cos (\Theta t+\lambda) ; \Theta^{2}=c^{2}+(a-b)^{2} \mu^{-1} .
\end{gathered}
$$

It is easy to see that the problem of achieving the goal is determined only by the exponential formula (13). For $b>a$ the solution asymptotically tends to zero and, taking into account the remarks made, the prevalence of realists over conformists leads to success (Fig. 7).

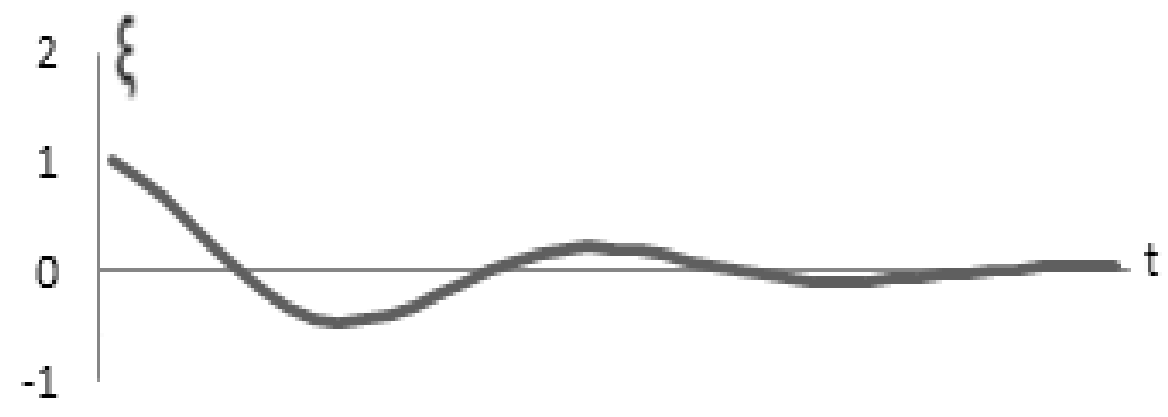

Fig. 7. Goal (stability $\xi \approx 0$ ) can be achieved

If $a>b$, then we will get the case, shown in Fig. 7 - the success is impossible.

If $a \approx b$, an unstable situation incurs. From the model point of view, it is necessary to take into account nonlinear terms and a number of other refinements and modifications of the model. 


\section{Conclusions}

Thus, we can make the following conclusion. The qualitative possibility of achieving the goal does not at all depend on the performance factor "c". That is, employees, who are not able to monitor the tendency of changing the function of success, are not important for its achievement. On the other hand, they are not hindrances, such as, for example, conformists, who asymptotically irrevocably lead the collective away from achieving success.

Only realists in the collective can lead to success achievement.

\section{References}

[1] Kaplan R.S., Norton D.R “The Balanced Scorecard: Translating Strategy into Action” Boston: HBS Press, 1996.

[2] Поспелов Г.С., Ириков В.А., Курилов В.А. Процедуры и алгоритмы формирования комплексных программ (The procedures and algorithms of formation of the integrated programs) -Moscow:Publishing House"NAUKA", 1985. (In Russian).

[3] Ириков В.А. Активное инновационное антикризисное управление: успешный опыт и рекомендации по его использованию. (Active innovative crisis management: successful experience and recommendations for its use) - Moscow: "Moscow Institute of Energy Security and Energy Conservation”, 2009 г, 84 p.(In Russian)

[4] Ириков В.А., Тренев В.Н. Распределенные системы принятия решений (Distributed systems decision making). - Moscow: Publishing House"NAUKA","Fizmatlit", 1999. (In Russian).

[5] Leontiev S.V., Masyutin S.A., Trenev V.N. "Strategies of success: a generalized experience of reformation of Russian industrial companies". Novosti Printing House, 2000. (In Russian).

[6] Irikov V.A., Novikov D.A., Trenev V.N. "A holistic structure of governmental and private management of innovative development as a means of doubling the pace of Russia's economic recovery and post-crisis growth". Russian Academy of Sciences Institute of Control Sciences, 2009, pp. 228.

[7] Burkov V. N., Goubko M., Korgin N., Novikov D. Introduction to Theory of Control in Organizations. - Boca Raton: CRC Press. 2015.

[8] Babitsky V.I., Krupenin V.L Vibration of Strongly Nonlinear Discontinuous Systems.Berlin: Springer-Verlag, 2001. 404 p.

[9] Полянин А. Д. Справочник по линейным уравнениям математической физики. (Handbook of linear equations of mathematical physics) - Moscow: Publishing House "Fizmatlit", 2001. (In Russian). 